\title{
Fransızca A1 Dil Düzeyinde Kelime Öğretiminde "Le Fle Pour Les Curıeux" İnternet Sitesinin Kullanımı Hakkında Öğrenci Görüşlerinin Belirlenmesi
}

\section{Öğr. Gör. Dr. Senem Seda Şahenk ${ }^{1 *}$}

Geliş tarihi: 30.08 .2019

Kabul tarihi: 10.09 .2019

\section{Atıf bilgisi:}

IBAD Sosyal Bilimler Dergisi

Sayı: Özel Sayı Sayfa: $198-216$

Yıl: 2019

This article was checked by iThenticate. Similarity Index $17 \%$.

${ }^{1}$ Marmara Üniversitesi, Türkiye, senemseda78@gmail.com,

ORCID ID 0000-0001-7861-430X

* Sorumlu yazar

\section{$\ddot{O z z}$}

$\mathrm{Bu}$ araștırmanın problem cümlesi şu șekilde dile getirilebilir: "Fransızca A1 dil düzeyinde kelime öğretimi sürecinde "Le FLE Pour Les Curieux" internet sitesi kullanımı hakkında öğrencilerin görüșleri nelerdir?” Bu çalıșmanın amacı Fransızca A1 dil düzeyinde kelime öğretimi sürecinde "Le FLE Pour Les Curieux" internet sitesi kullanımı hakkında öğrencilerin görüşlerinin tespit edilmesidir. Bu çalışmada nitel yöntem kullanılmıștır. Bu çalıșma bir durum çalıșmasıdır. Araştırmada 2017 2018 eğitim-öğretim yılının güz döneminde Marmara Üniversitesi İngilizce Öğretmenliği bilim dalı 3. sınıfta ikinci yabancı dil olarak Fransızca öğrenen 10 öğrenciyle yüz yüze görüşmeler yapılmıştır. Sonuç olarak öğrencilerin çoğunluğu hem Fransızca' ya yönelik ilgi, istek ve motivasyonlarının arttığını hem de dinleme, okuma, konuşma ve yazma becerilerinde önemli gelişmeler gördüklerini savunmuşlardır. Ayrıca öğrencilerin birkaçı ise hem araştırmacının zaman yönetiminde zorluk yaşadığını hem de internet destekli gerçekleştirilen aktivitelerin sürecinin uzatılması faydalı olabileceğini ifade etmişlerdir.

Anahtar Kelimeler: Fransızca öğretimi, A1 dil düzeyi, İnternet destekli derslerle kelime öğretimi. 
To Determine the Views of Students Using the Internet Site "Le Fle Pour Les Curieux" for Teaching the French Vocabulary in A1 Language Level

\section{Lec. Dr. Senem Seda Şahenk ${ }^{1 *}$}

First received: 30.08 .2019

Accepted: 10.09 .2019

\section{Citation:}

IBAD Journal of Social Sciences

Issue: Special Issue Pages: 198-216

Year: 2019

This article was checked by iThenticate. Similarity Index $17 \%$.

${ }^{1}$ Marmara University, Turkey, senemseda78@gmail.com,

ORCID ID 0000-0001-7861-430X

* Corresponding Author

\begin{abstract}
The problem sentence can be expressed as follows: "What are the students "opinions about the use of the website "Le FLE Pour Les Curieux" in the process of the vocabulary teaching at French A1 language level?" The aim of this study is to determine the views of the university students using the internet site "Le FLE Pour Les Curieux". Qualitative method was used in the study. This research is a case study. This research was conducted in the fall semester of the 2017-2018 academic year, face-to-face interviews with 10 students learning French as a second foreign language in the 3rd year of the Marmara University English Language Teaching Department. As a result, the majority of students argued that their interest, desire and motivation towards French had increased and they had seen significant improvements in their listening, reading, speaking and writing skills. In addition, a few of the students affirmed that the researcher had difficulty in time management and that it would be beneficial to extend the process of internet-supported activities.
\end{abstract}

Keywords: Teaching French, A1 Language Level, Vocabulary Teaching in Internet-based Lessons. 


\section{GíRIŞ}

Günümüzde tüm dünyada var olan globalleşme ve teknolojik gelişmelerin etkisiyle bireyler çok dilliliğe ve çok kültürlülük anlayışlarına doğru yöneldikleri gözlemlenmektedir. Bu doğrultuda tüm vatandaşların toplumda saygın bir yere sahip olmak ve aynı zamanda iyi bir meslek ve pozisyon edinmek amacıyla iki ve daha fazla yabancı dil öğrenmeye ihtiyaç duymaktadır. 21. yüzyılda bilgi çağında hızla gelişen tüm dünya ülkelerinde tüm alanlardaki gelişmeleri yakından takip edebilmek hedefiyle bireyler yabancı dil(ler)i ögrenmeye yönelik yeni yöntem ve stratejilere başvurmaktadırlar (Lothering \& Jenson, 2011). Ayrıca 21. yüzyılda yabancı dil bilmek hem çok dilli ve çok kültürlü olmanın ön koşulu olarak algılanırken hem de kişisel gelişimi destekleyen bir zorunluluk haline dönüşmüştür (Erişkon Cangil, 2004).

Yabancı dil eğitimi denince ilk akla gelen çoğu zaman İngilizcedir. Fakat bunun yanı sıra yabancı dil olarak İngilizce dışında Fransızca eğitim ve öğretimi gerekli ve önemli olarak algılanabilir. Çünkü Fransızca 6 kıtada Fransa dışında birçok ülkede (Kanada, Belçika, İsviçre, Cezayir, Fas vs. gibi ülkeler...) resmi dil olarak kullanılmaktadır. Ayrıca tüm dünya ülkelerinde eğitim ve öğretimi verilen yabancı diller arasında yer almaktadır. Tüm dünyada yaklaşık olarak 300.000.0000 kişi tarafından Fransızca konuşulmaktadır (La langue Française dans le monde, 2014).

$\mathrm{Bu}$ bağlamda yabancı dil öğrenen tüm bireyler başlangıçta kelime bilgilerini geliştirmeye yönelik yöntemlere önem vermeleri gerekmektedir. Yabancı dil sınıflarında kelime öğretim yöntemleriyle yabancı dil öğrenmeye çabalayan tüm bireyler hem kelimelerin anlamsal, işlevsel, bağlamsal ve dil bilgisel gibi birçok yönünü keşfetmek amacındadır (Duran \& Bitir, 2017). Yabancı dilde kelime ögretimi dil öğretiminin en önemli aşamalar arasında yer alır. Dil öğreniminde bireylerin anlama, dinleme, yazma ve okuma etkinliklerini akıcı bir şekilde yapılabilmeleri kelime dağarcığının genişliği ile doğrudan ilişkilidir (Günday, 2015). Yabancı dil eğitim ve öğretimi sürecinde kelimelerin anlamlarını hareketlerle, nesnelerin kendisi gösterilerek, nesnelerin yerini tutan resim veya fotoğrafları göstererek, sözcüğün ana dildeki karşılığını/tanımını vererek, hedef dilde bu sözcüğü açıklayarak ve bağlam ipuçlarından yararlanılarak ögretilebilir (Nation, 2001). Günümüzde yaşanan bilgi çağı ve küreselleşme kapsamında teknolojinin gelişimiyle birlikte yabancı dil eğitimi ve öğretimi sürecinde kelime öğretimi aşamasında teknolojiden yararlanması son derece önemli ve gereklidir. $\mathrm{Bu}$ nedenlerden dolayı yabancı dil kelime öğretimi aşamasında kelime öğretimi sürecinde bilgisayar ve/veya internet destekli derslerin yürütülmesi temel bir ihtiyaçtır (Ayaz \& Gürsoy, 2002).

Avrupa Ortak Dil Kriterlerine göre mevcut olan 6 dil düzeyi aşağıda gösterilmektedir:

\section{Şekil 1: Avrupa Ortak Dil Kriterleri 6 Dil Düzeyi}

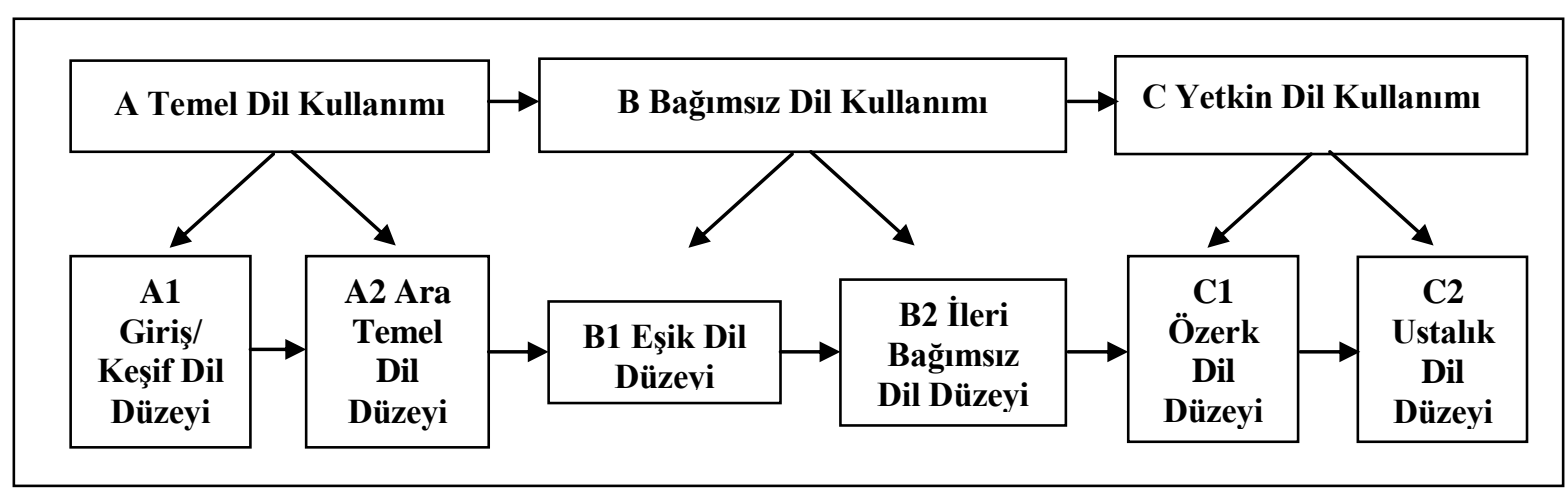

(Diller İçin Ortak Başvuru Metni Öğrenme-Öğretme-Değerlendirme, 2001)

A1 dil düzeyinde (Giriş /Keşif dil düzeyinde) günlük hayatta yapılan ait olan selamlaşma, tanışma, alışveriş vs. gibi... eylemlerle ilişkili kelimelerin öğretilmesi gereklidir (Diller İçin Ortak Başvuru

Metni Öğrenme-Öğretme-Değerlendirme, 2001). Bu araştırma çerçevesinde Fransızca A1 dil düzeyinde "Le point du FLE" internet sitesi kullanılarak dersler düzenlenmiştir. 
Yabancı dil(ler)in eğitimi sürecinde kelime öğretim alanlarıyla ilgili ulusal ve uluslararası literatür incelendiğinde daha önce yayınlanmış araştırmalar arasında ilk grupta İngilizce eğitiminde kelime bilgisinin geliştirilmesine yönelik yayınlanmış çalışmalar mevcuttur (Zengin, 2019; Akmaz; AlBidawi, 2018; Ketevan, 2018; Zorluel Özer \& Cabaroğlu, 2018; Albar, 2017; Demir, 2017; Gök, 2017; Kansızoğlu, 2017; Maghsoudi \& Golshan, 2017; Mashhadi Heidar \& Sadeghzadeh Hemayati, 2017; Patahuddin, Syawal \& Bin-Tahir, 2017; Patterson, 2017; Baldoumi, 2016; Işık, 2016; Işık \& Semerci, 2016; Tosun, 2016; Anadol, 2015; Başören, 2015; Çelik, 2015; Ebrahimi \& Azhideh, 2015; Hemmati \& Asmawi, 2015; Hişmanoğlu, 2015; Şimşek, 2015; Wang, Theng \& Chen, 2015; AlDarayseh, 2014; Kocaman \& Kızılkaya Cumaoğlu, 2014; Özdemir, 2014; Sarı Atilla, 2014; Aktekin \& Güven, 2013; Amirian \& Heshmatifar, 2013; Shintani, 2013; Tayhani Temizgöl, 2013; Akkakason, 2012; Gülten, 2012; Heidari, \& Tavakoli, 2012; Ping \& Siraj, 2012; Arjomand, \& Sharififar, 2011; Zhang, Song \& Burston, 2011; A'lipour \&Ketabİ, 2010; Asgari, 2010; Nacera, 2010; Noor \& Amir, 2009; Erten \& Tekin, 2008; Kim, 2008; Şimşek, 2008; Atilay, 2007; Bruton, 2007; Chen, \& Chung, 2007; Mohseni-Far, 2007; Stockwell, 2007; Webb, 2007; Yazdi, 2007; Hasbún, 2005; Ivone, 2005; Tokaç, 2005; Tang \& Nesi, 2003; Laufer \& Hulstijn, 2001). Ardından Fransızca öğretiminde kelime bilgisinin zenginleştirilmesine yönelik araştırmaların varlığı göze çarpmaktadır (Aycan \& Günday, 2018; Abu-Liala, 2017; Kuşçu, 2017; Şahenk Erkan, 2017; Lavoie, 2015; Bozavl1, 2014; Monge, 2013; Tar, 2013; Yetiş, 2013; Scheidecker, 2011; Lahlou, 2009; Marin, 2005; Rodrigues, 2005; Yılmaz, 2000). Bunun yanı sıra yabancı dil olarak Türkçe eğitimi ve öğretimi alanında kelime bilgisinin geliştirilmesi yönelik yapılmış olan çalışmalar bulunmaktadır (Başutku, 2018; Göçmen, 2018; Gün \& Günay, 2018; Memiş, 2018a; Pilanc1 \& Saltuk, 2018; Saydam, 2018; Demirekin, 2017; Aslan \& Coşkun, 2016; Aytan \& Başal, 2016; Sarani \& Shirzaei, 2016; Akbulut \& Yaylı 2015; Yığın, 2013; Arslan \& Gürdal, 2012; Apaydın, 2007). Bir diğer grupta ise yabancı dil sinıflarında başvurulabilecek kelime öğretim yöntem ve stratejilerini inceleyen araştırmaların varllğ 1 söz konusudur (Çevik vd, 2018; Memiş, 2018b; Sarı̈ül, 2017; Pamukçu \& Akbaraov, 2016; Şahinler Albayrak, 2015; Turgut, 2006; Öztürk, 2005; Genç, 2004). Ayrıca yabancı dil sınıflarında A1 dil düzeyine yönelik oluşturulmuş çalışmalar mevcuttur (Göçmen 2018; Gün \& Günay, 2018; Özkan Elgün, 2018; Pilancı \& Saltuk, 2018; Mısır, 2017; Özüdoğru, 2016; Akbulut \& Yaylı 2015; Karataş, 2014; Özperçin, 2013; Candemir, 2012; Tükenmez, 2012; Yiğit, 2010; Durmaz Y1lmaz, 2005). Son grupta ise yabancı dil sınıflarında bilgisayar ve internet destekli öğretim yöntemleriyle ilgili daha önceden geliştirilmiş olan çalışmalar şunlardır (Loewen, vd, 2019; Abarghoui \& Taki, 2018; Anjaniputra, A. G. \& Salsabila, 2018; Hajebi vd, 2018; Reed \& Hooper, 2018; Rossell-Aguilar, 2018; Bakla \& Çekiç, 2017; Gafni, Achituv, \& Rachmani, 2017; Kartal, Ova, \& Şentürk, 2016; Köse, Çimen \& Mede, 2016; T1lıç, 2016; Günday, 2016; Günday \& Aycan, 2016; Munday, 2016; Nushi \& Jenabzadeh, 2016; Walker, 2016; Lebrun \& Lacelle, 2014; Kritikou, Paradia \& Demestichas, 2013;Yetiş, 2013; Gorjan, 2012; Salengros-Iguenane, 2011; Salengros-Iguenane, 2010; Yetiş, 2009; Desmet, 2006; Salengros-Iguenane, 2006; Hayati, 2005; Tozcu \& Coady, 2004; Mangenot, 1998).

$\mathrm{Bu}$ kapsamda üzerinde çalışılmış bu araştırmanın problem cümlesi şu şekilde ifade edilebilir: "Fransızca A1 dil düzeyinde kelime öğretimi sürecinde "Le FLE Pour Les Curieux" internet sitesi kullanımı hakkında öğrencilerin görüşleri nelerdir?" Bu çalışmada Fransızca A1 dil düzeyinde kelime ögretimi sürecinde "Le FLE Pour Les Curieux" internet sitesi kullanımı hakkında öğrencilerin görüşleri neler olduğu belirlenmesi amaçlanmıştır.

\section{Fransızca A1 dil düzeyinde kelime öğretiminde "Le FLE Pour Les Curieux" internet sitesinin kapsamı ve kullanılma süreci}

"Le FLE Pour Les Curieux" internet sitesine ait olan "https://leflepourlescurieux.fr/guide-de-travaila1/" Fransızca A1 dil düzeyinde kelime öğretimine 2 bölümlük toplam 13 aktivite mevcuttur.

Birinci bölümde 6 ikinci bölümde ise 7 etkinlik bulunmaktadır. Birinci bölümde var olan 6 aktivite ve kapsamları aşağıda gösterilmektedir:

(i) Sayılar (4 aşamalı: 1-20, 21-60, 61-100 ve 1000-1.000.000.000 arasındaki sayılar ve 3 alıştırma) ve saatlerin öğretimi; 
(ii) Sıra sayıları (3 aşamalı: 1.-20., sıra sayılara ait kısaltmalar ve telaffuzlarıyla sıra sayılarının pekiştirilmesi ve 3 alıştırma) zaman zarfları ve tarihin söylenmesinin öğretimi;

(iii) Günler, aylar, mevsimler ve hava durumunun ifade edilmesi ve ardından 2 alıştırma;

(iv) Hislerden ve duygulardan bahsedilmesi ve 2 alıştırma;

(v) Ulaşım ve toplu taşıma araçları eğitimi, 1 video ve 3 alıştırma ve

(vi) Tatil, seyahat konaklama, tatilden geri dönme ve eve varış ait eylem ve temel ifadelerin ögretimiyle ardından 5 alıştırma bu çalışmalarla birlikte çevre ve ekoloji kelime bilgisi bulunmaktadır.

İkinci bölümde bulunan 7 etkinlikleri ve içerikleri aşağıda sıralanmaktadır:

(i) Şehir hayatına yönelik tüm kelime bilgisi ve 3 alıştırma;

(ii) Evin odaları ve 3 alıştırma;

(iii) Giysi \& aksesuarlar ve 2 alıştırma;

(iv) Bilgisayara ait kelime hazinesi ve 3 alıştırma

(v) Aile üyeleri, 4 alıştırma ve 1 video klip

(vi) Sebze \& meyveler ardından 2 alıştırma ve

(vii) İçecekler isimleri ve eylemlerin ardından 3 alıştırma mevcuttur.

"Le FLE Pour les Curieux" internet sitesi destekli Fransızca A1 kelime öğretim aktiviteleri 2017-2018 akademik yılının Güz dönemi süresince Fransızca (haftada 1 saat) olarak toplam 13 haftada gerçekleştirilmiştir.

\section{YÖNTEM}

$\mathrm{Bu}$ araştırmada nitel yöntem kullanılmıştır. Bu yöntem gözlem, görüşme ve doküman analizi gibi nitel veri toplama yöntemlerinin kullanıldığı, algılandığı ve olayların doğal ortamda gerçekçi ve bütüncül bir biçimde ortaya konmasına yönelik bir sürecin izlendiği araştırma türü olarak tanımlanabilir (Büyüköztürk vd, 2014). Nitel araştırma yönteminden yararlanılan bu araştırmada karmaşık kişisel ve duygusal sorunların ortaya çıkarılmasına yardımcı olması, istenilen bilginin eksiksiz olarak ve derinlemesine elde edilebilmesi, alınan cevaplara anında dönüt vermeye imkân sağlaması, değişik ve anında değişebilen koşullara uyabilme esnekliğine sahip olması, soruların sayısı ve sırasını değiştirme serbestliği tanıması gibi özelliklerinden dolayı yarı yapılandırılmış görüşme yöntemi kullanılmıştır (Yıldırım \& Şimşek, 2018; Karasar, 2007; Çepni, 2005; Ekiz, 2003). Yarı yapılandırılmış görüssmelerde ise sahip olduğu belli düzeydeki standartllğı ve esnekliği nedeniyle, yazmaya ve doldurmaya dayalı testler ve anketlerdeki sınırlılığı ortadan kaldırması ve belirli bir konuda derinlemesine bilgi edinmeye yardımcı olması nedeniyle araştırmacılar tarafından sıklıkla tercih edilir (Yıldırım \& Şimşek, 2018).

Ayrıca bu çalışmada durum çalışması tekniği kullanılmıştır. Durum çalışmalarında 'nası1' ve 'niçin' sorularını temel almakta, araştırmacının kontrol edemediği bir olgu ya da olayı derinliğine incelenmesine olanak vermektedir (Yıldırım \& Şimşek, 2018). Diğer bir deyişle Creswell (2007)'e göre durum çalışması; araştırmacının zaman içerisinde sınırlandırılmış bir veya birkaç durumu çoklu kaynakları içeren veri toplama araçları (gözlemler, görüşmeler, görsel-işitseller, dokümanlar, raporlar) ile analiz edilen durumların ve duruma bağlı temaların tanımlandığı nitel bir araştırma yaklaşımıdır. 


\section{Çalışma grubu}

Araştırmaya Marmara Üniversitesi İngilizce Öğretmenliği anabilim dalında 3. sınıfta ikinci yabancı dil olarak Fransızca öğrenen 10 öğrenciyle güz dönemi boyunca çalışmalar yapılmıştır. Tüm bu çalışmalar 2017-2018 akademik yılının Güz döneminde gerçekleştirilmiştir. Araştırma sürecinde görüşmeler yapılan çalışma grubunda yer alan öğrencilerin kişisel özellikleri aşağıdaki tabloda verilmektedir:

Tablo 2: Çalışma grubu (öğrencilerin) kodları ve kişisel özellikleri

\begin{tabular}{llccccc}
\hline & \multirow{2}{*}{ Kodlar } & \multicolumn{2}{c}{ Cinsiyet } & \multicolumn{3}{c}{ Yaş } \\
\cline { 3 - 6 } & & Kız & Erkek & 21-24 & 26-29 & 30 ve/veya 30+ \\
\hline $\mathbf{1}$ & F & X & & X & & X \\
$\mathbf{2}$ & R & X & & & & \\
$\mathbf{3}$ & A & & X & X & X & \\
$\mathbf{4}$ & N & X & & & X & \\
$\mathbf{5}$ & S & X & X & & & X \\
$\mathbf{6}$ & I & X & & X & & \\
7 & Z & X & & & & \\
$\mathbf{8}$ & C & X & & X & & \\
$\mathbf{9}$ & A1 & & X & X & X & \\
$\mathbf{1 0}$ & A1.1 & & X & & X \\
\hline
\end{tabular}

Yukarıdaki tabloda gösterildiği gibi çalışma grubunda yer alan 10 öğrencinin 6'sı kız ve 4'ü erkektir. Ayrıca bu öğrencilerin 4'ü 21-24 yaş, 3'ü 26-29 yaş arasında bulunurken 2'si ise 30 yaş veya 30 yaş üstündedirler.

\section{Veri toplama araçları}

Bu çalışmada iki tür veri toplama aracı kullanılmıştır:

(i) Kişisel özellikler formu: a/ Cinsiyet b/ Yaş

(ii) Yarı yapılandırılmış görüşme formu: a/ Olumlu b/ Olumsuz yönleri

Birinci veri toplama aracında yani kişisel bilgi formunda öğrencilerin cinsiyetlerini ve yaşlarını yazmaları istenmiştir.

Diğer veri toplama aracında ise "Yarı Yapılandırılmış Görüşme Formunda" aşağıda gösterilen iki soru bulunmaktadır:

\section{Şekil 2: Yarı yapılandırılmış görüşme formu}

\section{Yarı Yapılandırılmış Görüşme Formu}

1) Fransızca A1 dil düzeyinde kelime öğretiminin internet destekli olarak yürütülmesinin olumlu yönleri nelerdir?

2) Fransızca A1 dil düzeyinde kelime öğretiminin internet destekli olarak gerçekleştirilmesinin olumsuz yönleri nelerdir?

Şekil 2'de görüldüğü gibi yarı yapılandırılmış görüşme formunda şu 2 soru mevcuttur:

(i) Fransızca A1 dil düzeyinde kelime öğretiminin internet destekli olarak yürütülmesinin olumlu yönleri nelerdir?

(ii) Fransızca A1 dil düzeyinde kelime öğretiminin internet destekli olarak gerçekleştirilmesinin olumsuz yönleri nelerdir?

Yarı yapılandırılmış görüşme formu yüz yüze uygulanmıştır. Bu görüşmeler yaklaşık iki ders saati sürmüştür. Görüşme süreci konuşmalar ses cihazı ile kayıt edilmiştir. 


\section{Verilerin toplanması}

Çalışmaya ilişkin tüm veriler araştırmacılar tarafından 2017-2018 eğitim-öğretim yılının Güz Döneminde Marmara Üniversitesi İngilizce Öğretmenliği bilim dalı 3. sınıfta ikinci yabancı dil olarak Fransızca öğrenen 10 öğrenciyle yapılan yüz yüze görüşmeler neticesinde toplanmıştır. Araştırmaya katılan öğrencilere görüşmelere başlanmadan önce yapılacak görüşmelerin bilimsel amaçlı olduğu ve kimliklerinin hiçbir şekilde açıklanmayacağı belirtilmiştir.

\section{Verilerin analizi}

Araştırma sürecinde veriler toplanması için yapılan görüşmeler ses cihazı ile kayıt edilmiştir. Çalışma grubu oluşturan öğrencilere kodlar verilmiştir. Ardından alınan kayıtlar dinlenmiştir. Tüm kayıtlar yazıya dökülmüştür. Öğrencilerin kodlarıyla verdikleri cevaplar eşleştirilerek bir tablo oluşturulmuştur. $\mathrm{Bu}$ süreçte temalar ve alt temalar belirlenmiştir. Tüm bu verilerin yorumlanması dahilinde "Betimsel ve İçerik" analizleri kullanılmıştır. Betimsel analiz katılımcılar için çalışmak istedikleri farklı olgu ve olaylar hakkında özet bilgi elde edebilmeleri için sıklıkla gerçekleştirilen bir yöntemdir (Büyüköztürk vd, 2014). İçerik analizinde ise alanla ilgili (daha önceden yapılmış olan tüm yayınlanmış kitap, kitap bölümleri, makale ve bildiriler) eldeki yazılı tüm bilgilerin temel içerikleri ve içerdikleri mesajlar özetlenmektedir (Cohen, Manion \& Morrisson, 2007). İçerik analizi boyutunda güvenirliğin belirlenmesi amaciyla "Uyuşum Yüzdesi Formülü" kullanılmıştır. Uyuşum yüzdesi "Güvenirlik = Görüş birliği / (Görüş Birliği + Görüş Ayrıllğ 1$)$ x 100" formülünden yararlanılarak tespit edilmiştir (Miles \& Huberman, 1994). Güvenirlik hesaplamasındaki uyuşum yüzdesi \%70 ve üzerinde olduğunda toplanan tüm veriler kabul edilebilir olarak algılanır (Yıldırım \& Şimşek, 2018). Çalışmada, bu formül sonucunda kodlamalardaki uyuşum yüzdesi; birinci soru için 0.82 , ikinci soru için 0.90 ve toplamda iki soru için ise genel uyuşum düzeyi ise 0,86 olarak hesaplanmıştır. Oranların \%70'in üstünde olması kodlama güvenirlikleri için yeterli olduğu ispatlamıştır. Verilerin analizi sonucunda meydana getirilen tema ve alt temalar Tablo 3'de gösterilmektedir.

Tablo 3: Verilerin analizi sonucu tespit edilen tema ve alt temalar

Motivasyon oranları artmıştır.

İsteklerinin arttığını belirtmişlerdir.

İlgilerinin arttığını dile getirmişlerdir.

Motive olma düzeyleri iyi olduğunda bahsetmişlerdir:

Akademik başarılarında iyi sonuçlar edilmiştir.

Dinleme becerisine katkıları olduğu gözlemlenmiştir.

Okuma becerisine getirileri olduğu görülmüştür.

Konuşma becerisinde iyi sonuçlar elde edilmiştir.

Yazma becerisine katkıları olduğu savunulmuştur.

Zaman yönetiminde sorunlar yaşanmaktadır.

Zaman yönetiminde zorlanılmaktadır.

Yapılan etkinliklerde sürecin uzatılması yararlı olabilir.

\section{BULGULAR}

Çalışma grubunu oluşturan öğrencilerin görüşleri, gizlilik esasına dayanılarak, isimleri verilmeden kodlanarak aktarılmıştır. Bu bağlamda "Fransızca A1 dil düzeyinde" araştırmanın yürütülmesinden dolayı bu alanda çalışma yapıldığını doğrulayan "F", "R", “A", "N", "S", "I", “Z”, "C", “A1”, "A1.1" kodları toplam 10 öğrenciye verilmiştir.

Çalışmanın bu bölümünde görüşme formunda bulunan sorular alt problemlere göre gruplandırılarak bulgular belirlenmiştir.

"Le FLE Pour les Curieux" İnternet Sitesi Destekli Yapılan Fransızca A1 Dil Düzeyinde Kelime Öğretimi Etkinliklerinin Olumlu Yönleri

$\mathrm{Bu}$ alt problem paralelinde görüşme formundaki soru, " Le FLE Pour les Curieux" internet sitesi destekli yapılan Fransızca A1 dil düzeyinde kelime öğretimi etkinliklerinin olumlu yönleri nelerdir?" şeklindedir. $\mathrm{Bu}$ alt probleme bağlantılı olarak alınan yanıtların analizi sonucunda yedi alt tema 
belirlenmiştir: "istek, ilgi ve motivasyonları artmış aynı zamanda dinleme, okuma, konuşma ve yazma becerilerinde gelişmeler" tespit edilmiştir. Öğrencilerin çoğunluğu "F", "R", "N", "S", "A" ve "A1" kodlu öğrenciler (7 öğrenci) hem Fransızca' ya yönelik ilgi, istek ve motivasyonlarının arttığını hem de dinleme, okuma, konuşma ve yazma becerilerinde gelişmeler tespit ettiklerini ifade etmişlerdir.

\section{"Le FLE Pour les Curieux" İnternet Sitesi Destekli Yapılan Fransızca A1 Dil Düzeyinde Kelime Öğretimi Düzenlenen Aktivitelerin Olumsuz Yönleri}

$\mathrm{Bu}$ alt problem doğrultusunda görüşme formundaki soru, " Le FLE Pour les Curieux" internet sitesi destekli yapılan Fransızca A1 dil düzeyinde kelime öğretimi etkinliklerinin olumsuz yönleri nelerdir?" şeklindedir. Bu alt problemle ilişkili olarak elde edilen cevapların analizi sonucunda iki alt tema belirlenmiştir: "zaman yönetiminde zorlanılırken yapılan etkinliklerde sürecin uzatılması yararlı olabilir" olduğu savunulmuştur. Öğrencilerin birkaçı "I", "Z” ve "A1.1” kodlu öğrenciler (3 öğrenci) araştırmacının zaman yönetiminde zorlandığını ifade ederken iki öğrenci ise " $F$ " ve "S" yapılan etkinliklerin sürecinin uzatılması yararlı olabileceğini” savunmuşlardır.

\section{SONUÇ, TARTIŞMA VE ÖNERILER}

$\mathrm{Bu}$ araştırmanın sonuçları aşağıda sıralanmaktadır:

(i) Öğrencilerin çoğunluğu "F", "R", "N", "S”, “A” ve "A1” kodlu öğrenciler (7 öğrenci) Fransızca' ya yönelik ilgi, istek ve motivasyonlarının arttığını savunmuşlardır.

(ii) Aynı zamanda yukarıda kodları verilen 7 öğrenci "F", "R", "N", "S", "A" ve "A1" dinleme, okuma, konuşma ve yazma becerilerinde ilerlemeler kaydettiklerini dile getirmişlerdir.

(iii) Öğrencilerin birkaçı ise "I", "Z” ve "A1.1” kodlu öğrenciler (3 öğrenci) araştırmacının zaman yönetiminde zorluk yaşadığını savunmuştur.

(iv) Ayrıca çalışma grubunda yer alan iki öğrenci " $F$ " ve "S" yapılan etkinliklerin sürecinin uzatılması yararlı olabileceğini" ifade etmişelerdir.

Aycan \& Günday (2018) oluşturdukları araştırmada yabancı dil olarak Fransızca eğitiminde kelime öğretimi sürecinde kullanılan ve kelime becerisinin geliştirilmesine olumlu yönde katkı sağladığı düşünülen etkileşimli yazılımların işlevsellikleri hakkında bilgi sunulmasını hedeflemişlerdir. $\mathrm{Bu}$ çalı̧̧mada "Amélioration du Français", "Multidictnet", "https://tr.duolingo.com/", "https://www.lingq.com/", "https://www.fluentu.com/", "Le point du FLE" ve "Le Plaisir d'Apprendre" internet sitelerinin kullanımın Fransızca öğretimine olabilecek yararları belirlenmeye çalışılmıştır. Sonuçta yukarıda sıralan bu internet siteleri eşliğinde Fransızca kelime öğretimi sayesinde öğrencilerin hem motivasyonlarının hem de akademik başarılarının arttı̆̆ gözlemlenmiştir. Aycan \& Günday'ın (2018) çalışmasında olduğu gibi bu çalışmada da internet destekli Fransızca eğitiminin kelime öğretimini olumlu yönde etkilediği tespit edilmiştir.

Günday (2016) yılında yayınladığı çalışmasında yabancı dil olarak Fransızca öğretimi sürecinde eğitsel ve özgün materyallerin ve "Le Point du FLE" internet sitesinin kullanımlarının ne tür katkılar sunabileceği tespit edilmesi amaçlamıştır. Sonuçta bu tür etkinliklerle hem öğrencilerin motivasyonlarının hem de akademik başarılarının arttığ gözlemlenmiştir. Geliştirilen bu çalışmayla Günday (2016)'da ortaya koyulmuş olan bu araştırmada da internet destekli yabancı dil olarak Fransızca kelime öğretimine olumlu sonuçlar belirlenmiştir.

Günday \& Aycan (2016) ortaya koydukları araştırmada "Flanet FLE" ve "English Page" internet sitelerinin kullanılmasıyla Fransızca ve İngilizce öğrenimine ne tür katkılar sağlayabileceği amaçlamışlardır. Sonuç olarak Fransızca ve İngilizce öğrenimi sürecinde hem aktif öğrenmeleri gerçekleştiği hem de akademik başarılarının arttığı gözlemlenmiştir. Günday \& Aycan'ın (2016) birlikte yayınladıkları araştırmada tespit edildiği gibi bu çalışmada da internet destekli yürütülen Fransızca kelime öğretimi etkinliklerinin öğrencilerin başarılarının olumlu yönde etkilediği görülmüştür. 
Kartal, Ova \& Şentürk (2016) tarafindan oluşturulmuş olan bu betimsel araştırma modeline dayanan çalışmada rastgele bir örneklem seçimiyle yabancı dil olarak Fransızca öğrenen öğrencilerin web araçları yoluyla dilsel yeti ve amaçlarını geliştirmek için ne sıklıkla otonom çalıştıklarının ortaya konması amaçlanmaktadır. Sonuç olarak, öğrencilerin dinleme-anlama ve konuşma yetilerini geliştirmek için en sıklıkla müzik ve film sitelerinden, yazma ve okuduğunu anlama yetileri için ise elektronik kitaplar ve Fransızca sözlüklerden yaralandıkları belirlenmiştir. Aynı zamanda Kartal, Ova \& Şentürk (2016) araştırmada ve bu çalı̧̧mada internet destekli Fransızca öğretimi sayesinde öğrencilerin dinleme ve konuşma becerilerinin geliştiği gözlemlenmiştir.

Köse, Çimen \& Mede (2016) tarafından yayınlanan bu araştırmada Fransızca öğrenimi sürecinde "Quizlet" internet sitesinin kullanım yararlarının tespit edilmesi amaçlamışlardır. Sonuçta Fransızca öğrenimi sürecinde "Quizlet" internet sitesinin kullanılmasıyla öğrencilerin Fransızca' da dört temel dil becerisinde (dinleme, okuma, konuşma ve yazma) önemli gelişmeler tespit edilmiştir. Ayrıca bu araştırmada olduğu gibi Köse, Çimen \& Mede (2016) çalışmasında internet destekli Fransızca ögretimi gerçekleştirilmesiyle öğrencilerin dört temel dil becerileri olan dinleme, okuma, konuşma ve yazma becerilerinde önemli ilerlemeler görülmüştür.

Lebrun \& Lacelle (2014) tarafindan yürütülmüş olan bu çalışmada internet destekli yapılan Fransızca öğretimi sürecinde getirilerinin neler olabileceği belirlenmesi amaçlanmıştır. Sonuç olarak internet destekli Fransızca öğretimi sayesinde Fransızca öğretiminin çağdaşlaştırılabildiği gözlemlenmiştir. Aynı zamanda bu araştırmada ve Lebrun \& Lacelle (2014) tarafindan geçekleştirilen bu çalışmada internet destekli derslerinin Fransızca öğretimine olumlu yansımaları olduğu gözlemlenmiştir.

Yetiş (2013) tarafindan ortaya koyulan bu çalışmada Fransızca kelime öğretimi sürecinde internet kullanımının katkılarının belirlenmesi hedeflenmiştir. Elde edilen sonuçlara göre, İnternet kullanılmaya başlandığından itibaren öğrencilerin kısa sınav notlarıyla hesaplanan sınıf ortalamalarında bir artış görüldü ve bu artış sınıfta internet kullanımı sona erdikten sonra da düzeyini korumaya devam etti. Aynı zamanda Internet'in yabancı dil eğitiminde sözcük dağarcığını genişletmekte etkili olduğu görülmüştür. Geliştirilen bu araştırmada ve Yetiş (2013) çalışmasında internet destekli Fransızca kelime öğretimin olumlu sonuçlar elde etmeyi kolaylaştırdığı tespit edilmiştir.

Salengros-Iguenane (2010) yayınlanmış olan bu araştırmada internet destekli yürütülen Fransızca öğretim sürecinin bu boyuttaki katkılarının neler olabileceği tespit edilmesi amaçlanmıştır. Sonuç olarak Fransızca öğretinde internet destekli derslerin yürütülmesiyle öğrencilerin Fransızca öğrenmeye yönelik olan ilgi ve motivasyonlarının arttığı ve de akademik başarılarında olumlu gelişmeler görülmüştür. Oluşturulan bu çalışmada ve Salengros-Iguenane (2010) tarafindan ortaya koyulan bu araştırmada internet destekli dersler düzenlenirken öğrencilerin Fransızca öğrenmeye yönelik olan ilgi ve motivasyonlarının arttığı aynı zamanda akademik başarılarında ilerlemeler söz konusu olmuştur.

Yetiş (2009) meydana getirdiği bu betimsel çalışmanın amacı yabanc1 dil öğretimini/öğrenimini etkilediği tespit edilen teknolojik araçların kısa bir tarihçesini çıkararak uygulama, iletişim ve bilişim açısından zengin bir araç olan İnternetin yabancı dil öğretimindeki farklı kullanım şekillerini göstermektir. Sonuç olarak teknolojik araçlarının ve internet kullanılmasıyla öğrencilerin motivasyonlarının ve akademik başarılarının arttığı belirlenmiştir. Oluşturulan bu çalışmada ve Yetiş (2009) araştırmasında internet destekli Fransızca kelime öğretiminin öğrencilerin hem derse yönelik olan motivasyonlarını hem de akademik başarılarını arttırdığı görülmüştür.

$\mathrm{Bu}$ çalışmaya yönelik bu alandaki diğer araştırmacılar için geliştirilebilecek öneriler aşağıda verilmektedir:

(i) İnternet destekli organize edilen derslerle Fransızca A1 dil düzeyi kelime öğretimi süreci dışında Fransizca A2, B1, B2, C1 ve C2 dil düzeylerinde de internet destekli derslerin yürütülmesi alana getirebileceği katkılar analiz edilebilir.

(ii) İnternet destekli yürütülen etkinliklerle Fransızca A1 dil düzeyi kelime öğretimi boyutu haricinde dilbilgisi ve telaffuz öğretimine yönelik getirilerinin neler olabileceği incelenebilir. 
(iii) İnternet destekli yapılan tüm bu aktiviteler eşliğinde Fransızca A1 dil düzeyi kelime öğretimi süreci dışında İspanyolca, Almanca, Çince vs gibi... dil öğretimlerinde internet destekli derslerin gerçekleştirilmesinin alana ne tür katkılar sağlayabileceği belirlenebilir.

\section{KAYNAKÇA}

Abarghoui, M. A. \& Taki, S. (2018). Measuring the effectiveness of using "Memrise" on high school students' perceptions of learning EFL. Theory and Practice in Language Studies, 8(12), 17581765 .

Abu-Liala, Z. (2017). L'enseignement/apprentissage du vocabulaire français à un public arabophone de Jordanie: Propositions et recommandations didactiques. The Arabic Journal of Human and Social Sciences, 29, 372-384.

Académie de Nantes (2015). Développer le vocabulaire des élèves: Un protocole d'expérimentation. Eylül 2015, Fransa: Nantes, Mission Maîtrise de la langue Groupe départemental de la Mayenne. 9 Ağustos 2018 tarihinde https://www.pedagogie.ac-nantes.fr/eleves-allophones-enfants-duvoyage/articles/developper-le-vocabulaire-des-eleves-francophones-et-allophones939465.kjsp?RH=1418575933844 adresinden erişildi.

Akbulut, S. \& Yaylı, D. (2015). Yabancı dil olarak Türkçe öğretimi A1-A2 düzeyi ders kitapları üzerine bir izlence çalışması. Erzincan Üniversitesi Sosyal Bilimler Enstitüsü Dergisi (ERZSOSDE), Özel Sayı II, 35-46.

Akmaz Genç, İ. (2018). Etkileşimli kelime duvarı tekniğinin 4. sınıf öğrencilerinin İngilizce dersi kelime bilgisine ve derse yönelik tutumuna etkisi. Yayınlanmamış yüksek lisans tezi, Akdeniz Üniversitesi, Antalya.

Akkakoson, S. (2012) Raising strategic Awareness of Thai EFL students of Science and Technology disciplines through Metacognitive Strategy training. The Southeast Asian Journal of English Language Studies, 18(4), 35-47.

Aktekin, N. Ç. \& Güven, S. (2013). Examining the impact of vocabulary strategy training on adult EFL students. Mersin Üniversitesi Ĕ̈itim Fakültesi Dergisi, 9(2), 339-352.

Albar, R. (2017). The relationship between students' vocabulary size, foreign language anxiety, and their speaking ability (A correlational study at the seventh grade of SMP Islam Al-Azhar 3 Bintaro). Yayınlanmamış doktora tezi, Syarif Hidayatullah State Islamic University of Jakarta Faculty of Educational Sciences, Endonezya, Jakarta,.

Al-Bidawi, S. A. (2018). Vocabulary Learning Strategies (VLSs) preferred by Saudi EFL students. English Language Teaching, 11(12), 211-220.

Al-Darayseh, A. M. (2014). The impact of using explicit/implicit vocabulary teaching strategies on improving students' vocabulary and reading comprehension. Theory and Practice in Language Studies, 4(6), 1109-1118.

A'lipour, J. \& Ketabi, S. (2010). Teaching vocabulary in EFL classrooms: A tried-out technique. English Language Teaching, 3(3), 158-159.

Alptekin, C. (2007). Foreign language learning strategy choice: Naturalistic versus instructed. Language Acquisition Journal of Theory and Practice in Education, 3(1), 4-11.

Altıkulaçoğlu, S. (2010). Yabancı dil sınıflarında eşdizimli sözcük öğretimi ve anadilinin rolü. Dil Dergisi, 148, 37-52. 
Amirian, S. M. R. \& Heshmatifar, Z. (2013). The impact of using electronic dictionary on vocabulary learning and retention of Iranian EFL learners. International Journal of Research Studies in Educational Technology, 2(1), 35-44.

Anadol, H. (2015). Effectiveness of writing new words multiple times with their Turkish meanings technique for vocabulary retention in teaching English as a Foreign Language context with reference to teachers' reflections on this technique. Yayınlanmamış yüksek lisans tezi, Karadeniz Teknik Üniversitesi, Trabzon.

Anjaniputra, A. G. \& Salsabila, V. A. (2018). The merits of Quizlet for vocabulary learning at tertiary level. Indonesia EFL Journal, 4(2), 1-11.

Apaydın, D. (2007). Türkçe’nin yabancı dil olarak ögrretiminde sözcük ögrretimi üzerine bir yöntem denemesi. Yayınlanmamış yüksek lisans tezi, Ankara Üniversitesi, Ankara.

Arjomand, M. \& Sharififar, M. (2011). The most and least frequently used vocabulary learning strategies among Iranian EFL freshman students and its relationship to gender. Iranian EFL Journal, 7(1), 90-100.

Arslan, M. \& Gürdal, A. (2012). Yabancılara görsel ve işitsel araçlarla Türkçe kelime öğretim yöntemi. Kastamonu Ĕ̈itim Dergisi, 20(1), 255-270.

Asgari, A. (2010). The influence of informal language learning environment (parents and home environment) on the vocabulary learning strategies. Canadian Center for Science and Education. English Language and Literature Studies, 1(1), 7-13.

Aslan, E. \& Coşkun, O. (2016). Yabancılara Türkçe öğretiminde oyun yazılımları ile sözcük öğretimi. Turkish Studies, 11(3), 221-236.

Atilay, D. (2007). The use of songs in teaching vocabulary to young learners in a foreign language teaching. Yayınlanmamış yüksek lisans tezi, Çağ Üniversitesi, Mersin.

Avrupa Konseyi (2013). Diller için Avrupa Ortak Öneriler Çerçevesi öğrenim, ögretim ve değerlendirme. Avrupa Konseyi Modern Diller Bölümü, ISBN: 978-3-86375-083-1, Almanya: Franfurt/ Main TELC $\mathrm{GmbH}, \quad 19 \quad$ Ağustos 2018 tarihinde https://www.telc.net/fileadmin/user_upload/Publikationen/Diller_iain_Avrupa_Ortak_oneriler_AEeraev esi.pdf adresinden erişildi.

Ayaz, Y. \& Gürsoy, E. (2002). Bilgisayar destekli yabancı dil öğretimi için internet yazarlı̆̆ı. İstanbul: Alfa Yayınları.

Aycan, A. \& Günday, R. (2018). Interactive applications for developing vocabulary skill in learning French as a foreign language. International Journal of Languages' Education and Teaching (IJLET), 6(4), 579-586.

Aytan, T. \& Başal, A. (2016). Yabancılara Türkçe öğretiminde ulam temelli sözcük öğretiminin başarıya etkisi. EKEV Akademi Dergisi, 20 (65), 559-576. doi: http://dx.doi.org/10.17753/Ekev563.

Bakla, A., \& Çekiç, A. (2017). Using an online vocabulary memorization tool versus traditional vocabulary exercises. Ana Dili Ĕgitimi Dergisi, 5(4), 948-966.

Baldoumi, K. (2016). The employment of vocabulary learning strategies by young Greek learners of English: Differences in relation to gender and grade. Theoretical and Applied Linguistics, 21 (2), Selected Papers of the 21st International Symposium on Theoretical and Applied Linguistics (ISTAL 21), 504-515.

Başoğlu, E. B. \& Akdemir, Ö. (2010). A comparison of undergraduate students' English vocabulary learning: using mobile phones and flash cards. The Turkish Online Journal of Educational Technology (TOJET), 9(3), 1-7. 
Başören, M. T. (2015). Drama öğretim tekniğinin yabancı dil kelime öğretimine ve ögrrencilerin kelime ögrenmeye yönelik tutumlarına etkisi. Yayınlanmamış yüksek lisans tezi, Necmettin Erbakan Üniversitesi, Konya.

Başutku, S. (2018). Türkçe'nin yabancl dil olarak öğretiminde B1 düzeyinde kelime öğretimi. Yayınlanmamış yüksek lisans tezi, Başkent Üniversitesi, Ankara.

Bozavlı, E. (2014). Yabancı dil dersinde kelime öğretiminde görsel işitsel materyallerin etkinliğinin değerlendirilmesi (TV 5 Monde/7 jours sur la planete modeli). Electronic Turkish Studies, 9(12), 31-41.

Büyüköztürk, Ş., Kılıç Çakmak, E., Akgün, Ö. E., Karadeniz, Ş. \& Demirel, F. (2014). Bilimsel araştırma yöntemleri (8. Baskı). Ankara: PegemA Yayıncılık.

Bruton, A. (2007). Vocabulary learning from dictionary reference in collaborative EFL translational writing. System, 35, 353-367.

Büker, M. \& Zeytinkaya, D. (2013). Eş anlamlı ve zit anlamlı kelime öğretiminin dil edinimindeki yeri ve önemi. Electronic Turkish Studies, 8(10), 185-191.

Candemir, C. (2012). L'Analyse des éléments culturels figurant dans les méthodes de Français Langue Étrangère intitulées Salut I, II d'après la perspective actionnelle. Yayınlanmamış yüksek lisans tezi, Gazi Üniversitesi, Ankara.

Cellier, M. (2011). Le vocabulaire et son enseignement: Des outils pour structurer l'apprentissage du vocabulaire. Fransa: Paris, Ministère Education National, Eduscol, 8 Ağustos 2018 tarihinde https://cache.media.eduscol.education.fr/file/Dossier_vocabulaire/57/6/Micheline_Cellier_11120 2_C_201576.pdf adresinden erişildi.

Chen, C. M. \& Chung, C. J. (2007). Personalized mobile English vocabulary learning system based on item response theory and learning memory cycle. Computers \& Education, 51, 624-645.

Cohen, L., Manion, L. \& Morrison, K. (2007). Research methods in education (6. Baskı). ABD: New York, Routledge.

Creswell, J. W. (2007). Qualitative inquiry \& research design: Choosing among five approaches (2. Bask1). ABD: Sage Publications.

Çelik, A. (2015). Yabancı dilde dijital kelime öğretiminin lise öğrencilerinin yazmada kelime kullanımlarına etkisi. Yayınlanmamış yüksek lisans tezi, : Erciyes Üniversitesi.

Çepni, S. (2005). Araştırma ve proje çalışmalarına giriş. Trabzon: Üçyol Kültür Merkezi Yayınları.

Çevik, H., Orakc1, Ş., Aktan, O., Toraman, Ç. \& Ayçiçek, B. (2018). Ortaokul öğrencilerinin kelime öğrenme stratejilerinin çeşitli değişkenler bakımından incelenmesi. Abant İzzet Baysal Üniversitesi Ĕ̈itim Fakültesi Dergisi, 18(2), 796-814.

Demir, C. (2017). Lexical collocations in English: A comparative study of native and non-native scholars of English. Journal of Language and Linguistic Studies, 13(1), 75-87.

Demircioğlu, Ş. \& İşpir, O. A. (2016). İngilizce sözcük gruplarının öğretilmesinde yaratıcı drama yönteminin etkisi. Yaratıcı Drama Dergisi, 11(1), 105-116.

Demirekin, M. (2017). Yabancı dil olarak Türkçe’nin anlamlandırılmasında kelime ve dil öğrenme stratejileri kullanımı. Yayınlanmamış doktora tezi, Hacettepe Üniversitesi, Ankara.

Desmet, P. (2006). L'enseignement/apprentissage des langues à l'ère du numérique: tendances récentes et défis. Revue française de linguistique appliquée, 11(1), 119-138.

Diller İçin Ortak Başvuru Metni Öğrenme-Öğretme-Değerlendirme (2001). Ankara: MEB Yayınevi, 25 Ağustos 2018 tarihinde http://www.dilbilimi.net/ab_diller_icin_ortak_avrupa_basvuru_metni_meb_tarafindan.pdf adresinden erişildi. 
Durmaz Yılmaz, A. (2005). Avrupa Ortak Dil Kriterleri ve Dil Gelişim Dosyası uygulamalarının Türkiye'de varolan ilköğretim programının uygunluğuna değerlendirilmesi. Yayınlanmamış yüksek lisans tezi, Yıldız Teknik Üniversitesi, İstanbul.

Ebrahimi, Z. \& Azhideh, P. (2015). The effects of teaching vocabulary learning strategies on Iranian EFL learners 'vocabulary development. International Journal on Studies in English Language and Literature (IJSELL), 3(1), 57-64.

Ekiz, D. (2003). Eğitimde araştırma yöntem ve metotlarına giriş. Ankara: Anı Yayıncıllk.

Erişkon Cangil, B. (2004). Küreselleşme ve Avrupa Birliği yabancı dil eğitim politikaları 1şı̆̆ında 2000'li yıllarda Türkiye'de yabancı dil ve yabancı dil öğretmeni yetiştirme politikalarına bir bakış. İstanbul Üniversitesi Hasan Ali Yücel Eğitim Fakültesi Dergisi, 1(2), 273-282.

Erten, İ. H. \& Tekin, M. (2008). Effects on vocabulary acquisition of presenting new words in semantic sets versus semantically unrelated sets. System, 36, 407-422.

Eskelinen, M. (2017). Drama as a method of teaching EFL vocabulary: A material package for lower secondary school teachers. Yayınlanmamış yüksek lisans tezi, Jyväskylä, University of Jyväskylä Department of Language and Communication Studies English, Finlandiya.

Gafni, R., Achituv, D. \& Rachmani, G. (2017). Learning foreign languages using mobile applications. Journal Information Technology Education Research, 16, 301-371.

Genç, B. (2004). New trends in teaching and learning vocabulary. Çukurova Üniversitesi Sosyal Bilimler Enstitüsü Dergisi, 13(2), 117-126.

Gorjian, B. (2012). Teaching vocabulary through Web-Based Language Learning (WBLL) approach. Procedia Technology, 1, 334-339.

Göçmen, E. (2018). Yabancı dil olarak Türkçe öğretiminde otantik dokümanların kullanımı ve A1-A2 düzeyinde dil becerilerine etkisi. Yayınlanmamış doktora tezi, Hacettepe Üniversitesi, Ankara.

Gök, H. (2017). The implementation of various vocabulary teaching strategies on young learners. Yayınlanmamış yüksek lisans tezi, Bahçeşehir Üniversıtesi, Istanbul.

Göral, G. N. \& Görgen, İ. (201). İkinci dil kelime öğrenmede bilgi haritaları kullanımının öğrencilerin öğrenme ve hatırlama düzeyine etkisi. Journal of Human Sciences, 14(2), 2090-2098.

Gülten, D. (2012). Evaluating the efficiency of NLP applications for the teaching of English vocabulary of young learners: Adapting songs. Yayınlanmamış yüksek lisans tezi, Başkent Üniversitesi, Ankara.

Gün, M. \& Günay, C. Ö. (2018). Yunus Emre Enstitüsü Türkçe öğreniyorum A1.1 ve A1.2 seviye ders ve çalışma kitaplarının Avrupa Ortak Başvuru Metni (CEFR)'e ve 6-10 yaş grubu öğrencilerin seviyelerine uygunluğunun değerlendirilmesi. Route Educational and Social Science Journal, 5 (34), 749-758.

Günday, R. (2016). Utilisation des materiels didactiques et authentiques dans les methodes du FLE et le point du FLE. Pamukkale Üniversitesi Sosyal Bilimler Enstitüsü Dergisi, 25(1), 375-389.

Günday, R. \& Aycan, A. (2016). Öğrenme kuramları ve Flanet FLE ve English Page adlı yabancı dil eğitimi sitelerinde beceri geliştirme etkinlikleri. Ordu Üniversitesi Sosyal Bilimler Araştırmaları Dergisi, 6(15), 443-462.

Günday, R. (2015). Yabancı dil ögretiminde yaklaşımlar, yöntemler, teknikler ve multimedya araç ve materyalleri. Ankara: Favori Yayınları.

Gürdal, A. \& Arslan, M. (2011). Oyun ve bulmaca etkinlikleriyle yabancılara Türkçe kelime öğretim yöntemi. $1^{\text {st }}$ International Conference on Foreign Language Teaching and Applied Linguistics, Bosna Hersek: Saraybosna, 7 Ağustos 2018 tarihinde https://www.researchgate.net/profile/Mustafa_Arslan10/publication/267781450_OYUN_VE_B 
ULMACA_ETKGNLGKLERGYLE_YABANCILARA_TURKCE_KELGME_OGRETGM_Y ONTEMG/links/5514106a0cf2eda0df303e5e/OYUN-VE-BULMACAETKGNLGKLERGYLE-YABANCILARA-TUeRKCE-KELGME-OeGRETGMYOeNTEMG.pdf adresinden erişildi.

Hajebi, M., SeddiQ. T., Fahandezh, F., \& Salari, H. (2018). The role of web-based language teaching on vocabulary retention of adult pre-intermediate. Journal of Language Teaching and Research, 9(2), 372-378.

Hasbún, L. (2005). The effect of expli̇cìt vocabulary teaching on vocabulary acquisition and attitude towards reading. Revista Electrónica Actualidades Investigativas en Educación, 5(2), 1-25.

Hayati, A. (2005). The computer and language teaching. Asian EFL Journal: Professional Teaching Articles Collection, 4, 75-81.

Heidari, S. \& Tavakoli, M. (2012). The effects of repetition and L1 lexicalization on incidental vocabulary acquisition by Iranian EFL learners. The Language Learning Journal, 40, 1-16.

Hemmati, T., \& Asmawi, A. B. (2015). Incidental vocabulary learning and retention through reading a graded reader among Iranian EFL learners. The Online Journal of New Horizons in Education, $5(1), 72-86$.

Hişmanoğlu, M. (2015). Semiotic elements and difficulties in teaching vocabulary items. International Journal of Applied Semiotics, 5(1-2), 51-68.

Işık, İ. (2016). İlkokul 3. sınıf öğrencilerine eğitsel oyunlar ile İngilizce kelime öğretiminin akademik başarıya etkisi. Yayınlanmamış yüksek lisans tezi, Bartın Üniversitesi, Bartın.

Işık, İ. \& Semerci, N. (2016). İlkokul 3. sınıf öğrencilerine İngilizce kelime öğretiminde eğitsel oyunların akademik başarıya etkisi. Çankırı Karatekin Üniversitesi Sosyal Bilimler Enstitüsü Dergisi, 7(1), 787-804.

Ivone, F. M. (2005). Teaching English as a foreign language in Indonesia: The urge to improve classroom vocabulary instruction. TEFLIN Journal, 16(2), 195-208.

Kansizoğlu, H. B. (2017). The comparison of Vocabulary Teaching Methods in terms of their effect on vocabulary development: A Meta-Analytic Review. International Online Journal of Educational Sciences (IOJES), 9(3), 821-841.

Karasar, N. (2007). Bilimsel araştırma yöntemi. Ankara: Bilim Kitap Kırtasiye Yayınevi.

Karataş, F. (2014). 4. sınıf "Toko Demo" Almanca ders kitabının "Diller İçin Avrupa Ortak Başvuru Metni" kapsamında analiz edilmesi. Yayınlanmamış yüksek lisans tezi, Gazi Üniversitesi, Ankara.

Karatay, H. (2007). Kelime öğretimi. Gazi Eğitim Fakültesi Dergisi, 27(1), 141-153.

Kartal, E., Ova, G. \& Şentürk, A. (2016). Apprentissage autonome des étudiants en Français Langue étrangère à travers les outils du web. Uludă̆ Üniversitesi Eğitim Fakültesi Dergisi, 29(2), 383400.

Ketevan, K. (2018). Possible effects of the Teaching proficiency through Reading and Storytelling (TPRS) approach on very young learners' L2 vocabulary acquisition. Yayınlanmamuş yüksek lisans tezi, Yeditepe Üniversitesi, İstanbul.

Kim, Y. (2008). The role of task-induced involvement and learner proficiency in L2 vocabulary acquisition. Language Learning, 58(2), 285-325.

Kocaman, O., \& Kızılkaya Cumaoğlu, G. (2014). Eğitsel yazılım (DENIS) ve oyunlarla İngilizce kelime öğretiminin kelime öğrenme stratejilerine ve başarıya etkisi. Eğitim ve Bilim, 39 (176), 305-316.

Köksal, O. (2012). Öğrenme stratejilerinden bellek destekleyiciler İngilizce kelime öğrenme etkinlikleri. Konya: Meram, Eğitim Yayınevi. 
Köse, T. Çimen, E. \& Mede, E. (2016). Perceptions of EFL learners about using an online tool for vocabulary learning in EFL classrooms: A pilot Project in Turkey. International Conference Teaching and Learning English as an Additional Language GlobELT 2016, Nisan 2016, Türkiye: Antalya, Procedia - Social and Behavioral Sciences, 232, 362-372.

Kritikou, Y., Paradia, M. \& Demestichas, P. (2013). Cognitive web-based vocabulary learning system: The results of a pilot test of learning Greek as a second or foreign language. Procedia - Social and Behavioral Sciences, 141, 1339- 1345.

Kuşçu, E. (2017). Sözcük öğretimi üzerine değerlendirmeler ve Fransa Ulusal Bilimsel Araştırma Merkezi'nin (CNRS) görsel-anlambilimsel yorumu. Cumhuriyet Uluslararası Eğitim Dergisi, 6(2), 287-303.

Lahlou, S. (2009). La place actuelle de l'enseignement du vocabulaire dans les classes de FLE du secondaire hellénique:Attitudes et pratiques des enseignants. Synérgie Sud-Est Européen, 2, $37-$ 43.

La langue Française dans le monde (2014). Fransa: Paris, Edition Nathan. 21 Ağustos 2018 tarihinde https://www.francophonie.org/Langue-Francaise-2014/projet/Rapport-OIF-2014.pdf adresinden erişildi.

Laufer, B. \& Hulstijn, J. (2001). Incidental vocabulary acquisition in a second language: The construct of task induced involvement. Applied Linguistics, 22, 1-26.

Lavoie, C. (2015). Trois stratégies efficaces pour enseigner le vocabulaire: Une expérience en contexte scolaire innu. Revue Canadienne de Linguistique Appliquée, 18(1), 1-20.

Lebrun, M. \& Lacelle, N. (2014). L'ère numérique: un défi pour la didactique du FLE. Synergies Portugal, 2, 107-117.

Lotherington, H., \& Jenson, J. (2011). Teaching multimodal and digital literacy in L2 settings: New literacies, new basics, new pedagogies. Annual Review of Applied Linguistics, 31, 226-246.

Loewen, S. vd (2019). Mobile-assisted language learning: A Duolingo case study. The Journal of the European Association for Computer Assisted Language Learning (ReCALL), 31(3), 293-311.

Maghsoudi, N., \& Golshan, M. (2017). The relationship between vocabulary learning strategy preference and vocabulary size among Iranian EFL learners. International Journal of English Language \& Translation Studies, 5(3), 103-110.

Mahmood, A. (2017). The relationship between vocabulary learning strategies and vocabulary size of Iraqı EFL learners in terms of receptive word knowledge. Yayınlanmamış yüksek lisans tezi, Gaziantep Üniversitesi, Gaziantep.

Mangenot, F. (1998). Classification des apports d'Internet à l'apprentissage des langues. Apprentissage des Langues et Systèmes d'Information et de Communication, 1(2), 133-146.

Marin, M. (2005). Extraversion and the use of vocabulary learning strategies among university EFL students in Mexico. Yayınlanmamış doktora tezi, Colchester, University of Essex, ABD.

Mashhadi Heidar, D. \& Sadeghzadeh Hemayati, M. (2017). A comparative study of vocabulary learning strategies used by Marine Engineering students and Iranian EFL learners. Research in English Language Pedagogy (RELP), 5(1), 61-72.

Memiş, M. R. (2018a). The relationship between vocabulary learning strategies and vocabulary of learners of Turkish as foreign or second language. Educational Policy Analysis and Strategic Research, 13(4), 164-185.

Memiş, M. R. (2018b). Kelime hazinesi ve yabanc1 dilde kelime öğretimi üzerine. Turkish Studies, 13(19), 1273-1289. 
Misir, H. (2017). The analysis of A1 level speaking exam in terms of syntax: The effect of general competence on syntax in A1 level speaking. Journal of Language and Linguistic Studies, 13 (1), $27-40$.

Miles, M, B., \& Huberman, A. M. (1994). Qualitative data analysis: An expanded sourcebook. (2. Bask1). ABD: Sage, Thousand Oaks.

Mohseni-Far, M. (2007). Techniques and strategies utilized for vocabulary acquisition: The necessity to design a multifaceted framework with an instrucionally wise equilibrium. Porta Linguarum, 8, $137-152$.

Monge, A. L. Z. (2013). L'évolution de l'enseignement du vocabulaire dans la classe de L2. Revista de Lenguas Modernas, 19, 437-447.

Munday, P. (2016). The case for using Duolingo as part of the language classroom experience. Revista Iberoamericana de Educación a Distancia, 19, 83-101.

Nacera, A. (2010). Languages learning strategies and the vocabulary size. Procedia Social and Behavioral Sciences, 2, 4021-4025.

Nation, P. (2001). Learning vocabulary in another language. ABD: Cambridge, Cambridge University Press.

Noor, M. N \& Amir, Z., (2009). Exploring the vocabulary learning Strategies of EFL learners. Language and culture: Creating and fostering global communities. $7^{\text {th }}$ International Conference by the School of Studies and Lingustics Faculty of Social Sciences and Humanities, 313-327, Malezya: Bangi, University Kebangsaan Malaysia.

Nushi, M. \& Jenabzadeh, H. (2016). Busuu- the mobile app. TESL Reporter, 49(2), 30-38.

Özdemir, H. A. (2014). An empirical study on the contribution of mnemonic narrative chain method to vocabulary learning and retention of English preparatory students (Bellek destekleyicilerden öyküleme yönteminin hazırlık sinıfi ögrencilerinin kelime öğrenme ve hatırlamasına katkssı hakkında deneysel bir çalışma). Yayınlanmamış yüksek lisans tezi, Necmettin Erbakan Üniversitesi, Konya.

Özkan Elgün, İ. (2018). Illkokul 2. sinıf Ingilizce dersi öğretim programının eklektik modele göre değerlendirilmesi. Yayınlanmamış Doktora Tezi, Hacettepe Üniversitesi, Ankara.

Özperçin, A. (2013). Acquisition de la compétence pragmatique dans l'enseignement du FLE: Etude de l'acte d'argumentation dans le manuel "Alter Ego" (Acquisition of pragmatic competence in teaching FLE: Study of the act of argumentation in the manual "Alter Ego"). Yayınlanmamıs doktora tezi, İstanbul Üniversitesi, İstanbul.

Öztürk, M. (2005). Vocabulary teaching. Dil Dergisi, 133, 20-28.

Özüdoğru, F. (2016). İlkokul 2. sınıf İngilizce öğretim programının Diller İçin Avrupa Ortak Başvuru Metni doğrultusunda aydınlatıcı değerlendirme modeli ile değerlendirilmesi. Yayınlanmamış doktora tezi, Anadolu Üniversitesi, Eskişehir.

Pamukçu, A \& Akbaraov, A. A. (2016). Analysis of the relation between phonological memory and long term memory on foreign language vocabulary acquisition. Atatürk Üniversitesi Sosyal Bilimler Enstitüsü Dergisi, 20(1), 93-106.

Patahuddin, P., Syawal, S., \& Bin-Tahir, S. Z. (2017). Investigating Indonesian EFL learners' learning and acquiring English vocabulary. International Journal of English Linguistics, 7(4), 128-137.

Patterson, D. (2017). Vocabulary-building activities for the EFL classroom. LaoTESOL Conference Proceedings: Selected Papers, 164-171.

Pilancı, H. \& Saltuk, O. (2018). Yabancılara Türkçe öğretiminde dilbilgisi içeriğini etkileyen faktörler: A1, A2 düzeyleri. International Journal of Humanities and Education, 4(9), 122-149. 
Ping, A. M. \& Siraj, S. (2012). Exploring selfregulatory strategies for vocabulary learning among Chinese EFL learners. Procedia - Social and Behavioral Sciences, 47, 1211-1215.

Reed, J. T. \& Hooper, D. (2018). Student perceptions of mobile learning of high frequency vocabulary using the "Memrise" app. The Journal of Kanda University of International Studies, 30, 351371.

Rodrigues, C. (2005). Aide à l'apprentissage du vocabulaire dans un environnement hypermédia en Français langue étrangère. Yayınlanmamış doktora tezi, Clermont-Ferrand, Université Blaise Pascal - Clermont-Ferrand II UFR Lettres et Sciences Humaines, Fransa.

Rossell-Aguilar, F. (2018). Autonomous language learning through a mobile application: A user evaluation of the Busuu app. Computer Assisted Language Learning, 31(8), 854-881.

Salengros-Iguenane, I. (2011). Pertinence d'une approche culturelle appuyée sur Internet dans une grande école. Apprendre les langues à l'université au $21^{\text {ème }}$ siècle. Haziran 2011, Fransa: Paris, HAL Id: edutice-00942674.

Salengros-Iguenane, I. (2010). FLE Internet et approche culturelle. Une recherche à l'Ecole nationale des ponts et chaussées. Linguistique. Yayınlanmamış Doktora Tezi, Marsilya, Université de Provence - Aix-Marseille I Sciences du Langage Français Langue Étrangère et Seconde. Français. fftel-00556669f, Fransa.

Salengros-Iguenane, I. (2006). Approche culturelle et Internet en classe de FLE: Exemple d'une pratique à l'École nationale des ponts et chaussées. Apprentissage des langues et systèmes d'information et de communication (Alsic), 9, 161-180.

Sarani, A. \& Shirzaei, H. (2016). A comparative study of vocabulary learning strategies employed by Iranian undergraduate and postgraduate EFL learners with a focus on motivation. Indonesian Journal of EFL and Linguistics, 1(1), 33-45.

Sar1 Atilla, F. (2014). A case study on the benefits of using songs in teaching vocabulary by young learners of English. Yayınlanmamış yüksek lisans tezi, Çağ Üniversitesi, Mersin.

Sarıgül, E. (2017). Yabancı dil öğretiminde sözcük öğretimi ve öğrenimi sürecine genel bir bakış. The Journal of Academic Social Science Studies (JASS), 54, 91-104.

Saydam, M. (2018). Kelime ögrretimi stratejileri açısından yabancı dil olarak Türkçe öğretimi kitapları üzerine bir araştırma. Yayınlanmamış Yüksek Lisans Tezi, Yıldız Teknik Üniversitesi, İstanbul.

Scheidecker, C. (2011). Mémorisation du lexique: Apport des neurosciences cognitives. Yayınlanmamış Yüksek Lisans Tezi, Grenoble, Université Stendhal Grenoble III Spécialité FLE-FLM, Fransa.

Shintani, N. (2013). The effect of focus on form and focus on forms instruction on the acquisition of productive knowledge of L2 vocabulary by young beginning-level learners. TESOL Quarterly, $47(1), 36-62$.

Stockwell, G. (2007). Vocabulary on the move: Investigating an intelligent mobile phone-based vocabulary tutor. Computer Assisted Language Learning, 4, 365-383.

Şahenk Erkan, S. S. (2017). Internet-based French as a Foreign Language Vocabulary Learning: Academic Success and Opinions on FFL Learners. Universal Journal of Educational Research, 5(11), 2066-2073.

Şahinler Albayrak, M. (2015). Kinect kullanılan 3 boyutlu sanal gerçeklik uygulamalarının ilkokul ögrencilerinin yabancı dilde kelime ögrenimine etkisi. Yayımlanmamış yüksek lisans tezi, : Fatih Üniversitesi, İstanbul.

Şener, S. (2015). Vocabulary learning strategy preferences and vocabulary size of preservice English teachers. International Journal of Educational Researchers, 6(3), 15-30. 
Şimşek, H. (2015). Teaching college level English vocabulary through drama. Yayınlanmamış Yüksek Lisans Tezi, Çă̆ Üniversitesi, Mersin.

Şimşek, G. (2008). An effective way of teaching vocabulary: Collocations (Kelime ögretiminde etkin bir yöntem: Eşdizimlilikler). Yayınlanmamış yüksek lisans tezi, Selçuk Üniversitesi, Konya.

Tang, E. \& Nesi, H. (2003). Teaching vocabulary in two Chinese classrooms: School children's exposure to English words in Hong Kong and Guangzhou. Language Teaching Research, 7(1), 65-97.

Tar, M. (2013). L'acquisition du vocabulaire du Français Langue Étrangère dans les universités Nigérianes. Yayınlanmamış doktora tezi, Ota, Covenant University Département des Langues, Nijerya.

Tayhani Temizgöl, T. (2013). The effects of grammar translation method and communicative language teaching on vocabulary teaching. Yayınlanmamış Yüksek Lisans Tezi, Dokuz Eylül Üniversitesi, İzmir.

T1lıç, G. (2016). Yabancı dil öğreniminde kullanılan etkileşimli mobil uygulamalar: Duolingo örneği. Ĕgitim ve Öğretim Araştırmaları Dergisi, 5, Özel Sayı, 303-313.

Tokaç, A. (2005). A comparison of computer assisted vocabulary instruction teacher-led vocabulary instruction. Yayınlanmamış yüksek lisans tezi, Bilkent Üniversitesi, Ankara.

Tosun, B.C. (2016). Students' views on contextual vocabulary teaching: A constructivist view. Journal of Language and Linguistic Studies, 12(2), 87-106.

Tosuncuoğlu, İ. (2013). İngilizce kelimelerin oyunlarla öğretilmesi. Tarih Kültür ve Sanat Araştırmaları Dergisi, 2(4), 140-146.

Tozcu, A. \& Coady, J. (2004). Successful learning of frequent vocabulary through CALL also benefits reading comprehension and speed. Computer Assisted Language Learning, 17(5), 473-495.

Turgut, Ö. (2006). Yabancı dil dersinde pedagojik uygulama açısından sözcük ögrretimi ve sözcük dă̆arcı̆̆ını geliştirme yöntem ve tekniklerinin değerlendirilmesi. Yayınlanamamış yüksek lisans tezi, Fırat Üniversitesi, Elâzı̆̆.

Tükenmez, O. (2012). "Francofolie (2005)'” adl Franslzca ders kitabında yer alan okuma metinlerinin dil ögrenimindeki rolünün eylem odakl yaklaşıma göre incelenmesi. Yayınlanamamış yüksek lisans tezi, Gazi Üniversitesi, Ankara.

Walker, L. (2016). The impact of using Memrise on student perceptions of learning Latin vocabulary and on long-term memory of words. Journal of Classics Teaching, 16, 14-20.

Wang, B.-T., Teng, C.-W., \& Chen, H.-T. (2015). Using iPad to facilitate English vocabulary learning. International Journal of Information and Educational Technology, 5(2), 100-104.

Webb, S. (2007). The effects of repetition on vocabulary knowledge. Applied Linguistics, 28(1), 46-65.

Yazdi, M. (2013) Relationship between vocabulary learning strategies, perceptual learning styles and levels of vocabulary knowledge among Iranian EFL learners. Yayınlanmamış doktora tezi, Serdana, Universiti Putra Malaysia Faculty of Educational Studies, Malezya.

Yetiş, V. A. (2013). L'utilisation d'Internet pour l'enseignement du vocabulaire: Une étude pour le FLE. Hacettepe Üniversitesi Ĕgitim Fakültesi Dergisi, 39, 44-56.

Yetiş, V. A. (2009). Didactique des langues, évolution de la technologie et Internet. Çukurova Üniversitesi Sosyal Bilimler Enstitüsü Dergisi, 18(2), 40-56.

Yığın, M. (2013). Türkçenin ikinci dil olarak öğretiminde öğrencilerin kullandıkları kelime öğrenme stratejileri. Yayınlanmamış yüksek lisans tezi, Çanakkale Onsekiz Mart Üniversitesi, Çanakkale.

Yıldırım, A. \& Şimşek, H. (2018). Sosyal bilimlerde nitel araştırma yöntemleri. 18. Baskı, Ankara: Seçkin Yayıncılık. 
Y1lmaz, Z. (2000). L'enseignement du vocabulaire dans la classe du FLE (Fransizca yabancı dil sınıfinda sözcük ögretimi). Yayınlanmamış yüksek lisans tezi, Anadolu Üniversitesi, Eskişehir.

Yiğit, C. (2010). Avrupa Diller için Ortak Başvuru Çerçevesi ile ilköğretim 6. sinıf İngilizce öğretim programının karşılaştırılmalı analizi. Yayınlanmamış yüksek lisans tezi, Gaziantep Üniversitesi, Gaziantep.

Zengin, M. (2019). İngilizce kelime ögretiminde ĕgitsel bilgisayar oyunları kullanımının ögrencilerin başarı ve tutumlarına etkisi. Yayınlanmamış yüksek lisans tezi, Bursa Uludağ Üniversitesi, Bursa.

Zhang, H., Song W. \& Burston, J. (2011). Reexamining the effectiveness of vocabulary learning via mobile phones. The Turkish Online Journal of Educational Technology (TOJET), 10(3), 203 214.

Zorluel Özer, H. \& Cabaroğlu, N. (2018). Teaching vocabulary to visually impaired EFL learners. Çukurova Üniversitesi Eğitim Fakültesi Dergisi, 47(1), 151-163. 